\title{
A comparative analysis of cultural value orientations of Polish and Turkish employees: implications for international human resource management
}

Article

Accepted Version

Woldu, H. G., Patel, C. and Crawshaw, J. R. (2013) A comparative analysis of cultural value orientations of Polish and Turkish employees: implications for international human resource management. The International Journal of Human Resource Management, 24 (12). pp. 2452-2471. ISSN 14664399 doi: https://doi.org/10.1080/09585192.2013.781430 Available at https://centaur.reading.ac.uk/68840/

It is advisable to refer to the publisher's version if you intend to cite from the work. See Guidance on citing.

To link to this article DOI: http://dx.doi.org/10.1080/09585192.2013.781430

Publisher: Routledge

All outputs in CentAUR are protected by Intellectual Property Rights law, including copyright law. Copyright and IPR is retained by the creators or other copyright holders. Terms and conditions for use of this material are defined in the End User Agreement. 


\section{www.reading.ac.uk/centaur}

\section{CentAUR}

Central Archive at the University of Reading

Reading's research outputs online 


\title{
A comparative analysis of cultural value orientations of Polish and Turkish employees: implications for international human resource management
}

\author{
Habte G. Woldu ${ }^{\mathrm{a}} *{\text {, Charmi } \text { Patel }^{\mathrm{b}} \text { and Jonathan R. Crawshaw }}^{\mathrm{c}}$ \\ ${ }^{a}$ Organization, Strategy and International Management, Naveen Jindal School of Management, The University of Texas at Dallas, \\ Dallas, TX, USA; ${ }^{\mathrm{b}}$ Organization Studies Group, University of Edinburgh Business School, Edinburgh, UK; ${ }^{\mathrm{c}}$ Work and \\ Organizational Psychology Group, Aston Business School, Birmingham, UK
}

\begin{abstract}
This study empirically compares and contrasts the cultural value orientations of employees from Poland and Turkey by testing the compatibility of their values in three stages through seven cultural dimensions. The first phase of the study deals with the assessment of inter-country cultural value differences; the second phase investigates the intra-country cultural dynamics between selected demographic groups; and the third phase examines the inter-country cultural differences among the selected demographic groups of employees. The research has been conducted adopting the Maznevski, DiStephano, and Nason's (1995) version of cultural perspectives questionnaire with a sample of 744 (548 Polish and 196 Turkish) respondents. The results show significant cultural differences between Poland and Turkey, a presence of cultural dynamics among certain demographic groups within the country, and a mixture of convergence and divergence in the value systems of certain demographic groups both within and between the two nation(s). The research findings convey important messages to international human resource strategists in order for them to employ an effective and rational employment policy and business negotiation approach(es) to effectively operate in these countries. It also highlights that diversity of cultural values not only requires viewing each of them through cultural dimensions at a macro-level with a cross-country reference, but also requires monitoring their dynamics at the micro-level with reference to controlled demographic groups.
\end{abstract}

Keywords: convergence - divergence; cultural value orientations; Poland; Turkey

\section{Introduction}

The effective investment in, and trading with, new emerging markets and economies throws up a number of important HR challenges for multinational enterprises. Specifically, IHRM strategists are tasked with developing and implementing HR policies and practices across potentially very different national, institutional and cultural contexts (Sparrow, Schuler and Budhwar 2009). These policies are often required, therefore, to be responsive to local economic, institutional and cultural conditions, while also integrating and supporting their global activities (e.g. Budhwar 2012). The emergence of new economies is also likely to further diversify one's workforce as inward investment promotes a greater movement of both into and out of the respective countries (see Brewster, Mayrhofer and Morley 2000; Woldu and Budhwar 2011). These challenges thus make salient research that explores the cultural differences or similarities between these emerging nations and more established economies from which most inward investment and trading is most

\footnotetext{
*Corresponding author. Email: wolduh@utdallas.edu
} 

likely to come from. Such studies provide a greater understanding of societal difference in value orientations, helping IHRM practitioners develop appropriate and relevant policies and programs for their organization and management.

This paper focuses on two such, under-researched, emerging markets - Poland and Turkey - both of which have a growing economic and political influence, particularly within the EU region. Poland, of course, is a relatively new member of the EU, and Turkey has long been under consideration for future membership. By employing an empirical comparative cultural methodology, using Kluckholn and Strodtbeck's (1961) model of cultural value orientations, this paper aims to explore the extent to which the national identity of each country impacts the cultural values of its citizens and how these values may culturally be compatible with the western-dominated values found within the EU region.

In order to conduct a thorough analysis, we recognize the importance of exploring how consistent differences in value orientations are among different demographic cross-sections of Poland and Turkey. Recent research indicates that younger, more highly educated, and/or professional/managerial individuals tend to be more mobile and thus more likely to study/work abroad (e.g. Budhwar, Woldu and Ogbonna 2008). Such mobility and work opportunities suggest that these demographic groups may be more exposed to non-home country values and practices and thus perhaps be more likely to exhibit a greater cultural closeness (e.g. Adler and Gunderson 2008; Woldu and Budhwar 2011). We therefore also explore the evidence of potential cultural convergence among sub-demographic groups within and between the two countries, in particular focusing on age, gender, educational level and the managerial/professional cadre.

In doing so, our study contributes to the burgeoning empirical research exploring important cultural differences between nations (e.g. House, Hanges, Javindan, Dorfman and Gupta 2004). In particular, further empirical testing of Kluckholn and Strodtbeck's (1961) model of cultural value orientation and the related cultural perspectives questionnaire (CPQ) (Maznevski et al. 1995) is provided. The remainder of the paper is structured as follows: the next section summarizes prior research on cross-cultural management in general and cultural value orientations in particular, and presents our hypotheses. This is followed by details of the survey and its key findings. We then present our discussion and suggestions for future research.

An overview of cultural value dimensions' research frameworks

Much research within cross-cultural/comparative management has centered on the behavioral approach, as evidenced by Hofstede's (1983) influential work on cultural dimensions. Other cultural representations ensued include Schwartz's value inventory (Schwartz 1992), Trompenaars's (1994) cultural dimensions, Kluckholn and Strodtbeck (1961) value orientations and the GLOBE project (House et al. 2004). Most of these contributions have helped to study nations in some kind of logical country clusters based on their cultural value similarities. Furthermore, a number of investigations have been conducted to examine the value orientations of individuals and the impact of national culture on management practices (e.g. Ralston, Holt, Terpstra and Kai-Cheng 1997; Sparrow and Wu 1998; Nyambegera, Sparrow and Daniels 2000; Walumbwa and Lawler 2003; Woldu, Budhwar and Parkes 2006).

For our own analysis, we have borrowed the theoretical lens from the cultural value orientations framework proposed by Kuckholn and Strodtbeck (1961), which has since been developed by Maznevski et al. (1995). We investigate evidence of cultural 
convergence/divergence between Poland and Turkey across six cultural dimensions - the 'activity of thinking (AT)', the value of 'harmonious relations (RNH) and subjugation (RNS) with one's environment', the acceptance/nonacceptance of 'hierarchical (RH) and individualist (RI) relationships between people and the belief in the basic 'good/evil nature of human beings' (HNG) (see Table 1 for details on these cultural dimensions).

As Table 1 shows, there are 11 cultural dimensions, but their reliability scores meant that we focused only on six in our analysis. An examination of Cronbach's $a$ coefficients highlighted a relative weakness in the internal reliability of the remaining five cultural dimensions of the cultural scales measured in our study. To improve the reliability (and thus validity) of our study, we made the decision to focus our analysis only on those cultural dimensions that reported reliable scales above 0.68 , which is a minimum acceptable coefficient. In this study, AT (0.79), HNG (0.75), RH (0.76), RI (0.68), RNS (0.71) and RNH (0.69) met our criteria for scale/measure reliability (see also Maznevski et al. 1995; Woldu et al. 2006). We acknowledge leaving out the other dimensions from the investigation as a weakness of our study.

\section{Research hypotheses}

Building on the above proposed, the study probes to view the cultural value differences and similarities between Poland and Turkey in three phases.

The first phase deals with cross-country cultural differences between Poland and Turkey on six cultural dimensions. Due to a number of socio-cultural, economic and political legal differences between the two countries (e.g. Sachs 1993; Woldu et al. 2006; Ball, McCulloch, Fratz, Geringer and Minor 2008), it is safe to hypothesize that

Table 1. Cultural orientations and dimensions.

\footnotetext{
Activity

Doing (AD): People should continually engage in activity to accomplish tangible tasks. Thinking (AT): People should consider all aspects of a situation carefully and rationally before taking action.

Being (AB): People should be spontaneous and do everything in its own time.

Relationship to environment

Mastery (RNC): We should control, direct and change the environment around us.

Subjugation (RNS): We should not try to change the basic direction of the broader environment around us, and we should allow ourselves to be influenced by a larger natural or supernatural element.

Harmony (RNH): We should strive to maintain a balance among the elements of the environment, including ourselves.

Relationships among people

Individual (RI): Our primary responsibility is to and for ourselves as individuals, and next for our immediate families.

Collective (RC): Our primary responsibility is to and for a larger extended group of people, such as an extended family or society.

Hierarchical (RH): Power and responsibility are naturally unequally distributed throughout society; those higher in the hierarchy have power over and responsibility for those lower.

Nature of humans

Good/evil (HNG): The basic nature of people is essentially good (lower score) or evil (higher score). Changeable/unchangeable (HNC): The basic nature of human is changeable (higher score) from good to evil or vice versa, or nor changeable (lower score).
} 
Sources: Adopted from Maznevski et al. (1995). See also Kluckholn and Strodtbeck (1961). 
H1: Poland will differ significantly from Turkey on all cultural dimensions.

Furthermore, it will be instructive to view those cultural differences in view of the cultural orientation of the two countries. Poland, being part of the EU, is required to fulfill certain requirements and in particular the principle of implementing values that are commonly accepted in free market societies. Hence, Poland will not only differ from Turkey, but will also demonstrate values that are more compatible with the principles of a free market system. Earlier studies indicate that more economically advanced and democratic societies such as the USA (Woldu et al. 2006), Scandinavia and Northern Europe (e.g. Hofstede 1983; Laurent 1983; Adler and Gunderson 2008) tend to demonstrate weaker traits in activities of thinking (AT), hierarchical (RH) and individualist (RI) relations, categorization of people as naturally good/evil (HNG) and human relations (Woldu et al. 2006; Budhwar et al. 2008). Furthermore, Hofstede and Bond (1984) and Adler and Gunderson (2008) view western culture as being proshort-term business practice and demonstrating weak traits in long-term business relations, hence indicating lower cultural traits in both harmonious (RNH) and subjugative (RNS) relations to the environment.

Although Poland has been a member of the EU since 2004, it would be naive to suggest that its value system would converge fully with that of the EU within such a short period of time (Siemienska 1994; Kostera 1995; Woldu and Biederman 1999). However, it is worth noting that Poland existed under the rule of three powerful empires (the Austro-Hapsburg, Prussia and Russia) for over 120 years until its independence in 1918. Furthermore, the Poles have had extensive contacts with the West both before and after their independence (Weinstein and Obloj 2002). Indeed, many scholars believe that the communist system, which lasted only for 50 years, was not able to destroy the entrepreneurial spirit of the Polish people (e.g. Rajkiewicz 1998; Woldu et al. 2006), thus leading many to assume that Poland, on joining the EU, should be able to quickly demonstrate a positive cultural fit with the other EU nations.

Turkey, on the other hand, with its dominant Islamic religious context and no prior economic integration with the EU may be expected to be more culturally distant from Poland. Some of the acknowledged differences between Turkey and EU states (including Poland) include poor economic development, regional conflicts, uneven economic wealth distribution among regions, human rights violations, gender inequality and the increasing fear of radicalization of Islam (see Muftuler-Bac 2002; Ozbilgin and Woodward 2004). Based on such assumptions, the following hypothesis is proposed.

H2: The Polish cultural values will demonstrate higher traits in individualism (RI) and harmonious relations to nature (RNH), but lower on subjugative relations to nature (RNS), bias toward fellow human beings (HNG) and hierarchical relations (RH), and activity of thinking (AT) than Turkey.

Intra- and inter-country cultural differences

Apart from the continued importance of research that explores the existence (or not) of divergent cultural values between nations (e.g. Sparrow et al. 2009), we also acknowledge the growing call for cross-cultural research that investigates more micro-level, intra-national differences in cultural orientation (e.g. Tung and Verbeke 2010). As Tung (2008) states: 
the growing mobility of people, particularly skilled professionals and managers across countries, has contributed to the phenomenon of 'brain circulation', whereby people could 
leave their country of origin (COO) to settle in another country referred to as country of residence (COR), and then return to their COO or commute continually between their COO and COR. (p. 43)

Assuming cultural homogeneity across all people of a given nation-state thus threatens to oversimplify the potentially multi-layered and complex nature of national cultural values within a highly globalizing world economy (Budhwar et al. 2008).

The second phase of our study thus explores cultural values within the different demographic groups that, as past empirical research suggests, may be the key agent of cross-cultural convergence (Trompennars 1994; Adler and Gunderson 2008; Woldu and Budhwar 2011). In short, extant research indicates that the younger, more highly educated male, professional and managerial demographic groups of a nation-state tend to be the most geographically mobile and thus most likely to be exposed to different societal cultural values (e.g. Ball et al. 2008; Carbaugh 2009; Woldu and Budhwar 2011). Indeed, prior research has also shown that the more educated, managerial and younger members of nations reported significantly lower mean scores (than the older, non-educated and non-professional, and managerial groups) on the Kluckholn and Strodtbeck's cultural traits of collectivism, subjugation and hierarchy (Woldu et al. 2006). Based on such a premise, the following hypothesis is proposed.

H3: There will be significant intra-country differences across all cultural dimensions between the different demographic groups.

As previously stated, prior research suggests that members of certain demographic groups may have greater opportunities for geographic mobility and thus exposure to different sets of cultural norms and values (e.g. Adler and Gunderson 2008; Budhwar 2012). It is expected therefore that such demographic groups may be more likely to demonstrate an overlap of cultural values, with similar demographic groups of other nations (e.g. Woldu and Budhwar 2011). For example, the growth of expatriate positions and assignments reflects the increasing dominance of large multinational firms and trends for greater outsourcing of functions. Most expatriate positions are either technical/professional and/or managerial in nature. It follows that those in more professional and/or managerial positions are going to gain more exposure to overseas assignments. Moreover, Adler and Gunderson (2008) suggest that most willing expatriates tend to be of a younger generation, reflecting the greater overall mobility of this societal group.

Likewise, as more capital and technologies are crossing borders, the most educated and skilled labor is migrating to various prosperous regions of the world (Hoecklin 1995; Emrich, Denmark and Hartog 2004; Woldu and Budhwar 2011). Both Poland and Turkey are known for having a higher percentage of their young generation living and working in more advanced western countries (Benhabib and Isiksel 2006). Hence, it can be assumed that the diaspora from both countries will have a significant impact on the cultural attitude of both countries.

In order to test whether there is a greater cultural convergence between Poland and Turkey, there is a need for controlling demographic groups. These demographic groups are selected for analysis for two main reasons:

(1) They are representative of the overall sample population considering their ratio in the overall sample populations of the two countries (see Table 2).

(2) They are diverse enough to consider their values mirroring the national cultures of the respective countries they belong to. 
Table 2. Demographic details of the samples.

\begin{tabular}{|c|c|c|c|c|c|}
\hline \multirow[b]{2}{*}{ Characteristic } & \multirow[b]{2}{*}{ Category } & \multicolumn{2}{|c|}{ Poland } & \multicolumn{2}{|c|}{ Turkey } \\
\hline & & Number & Percentage & Number & Percentage \\
\hline \multirow[t]{2}{*}{ Gender } & Male & 249 & 42.6 & 116 & 63.4 \\
\hline & Female & 290 & 53.8 & 65 & 35.6 \\
\hline \multirow[t]{2}{*}{ Age structure } & 35 or younger & 274 & 51.2 & 140 & 74.9 \\
\hline & .35 & 48.8 & 48.8 & 47 & 25.1 \\
\hline \multirow{2}{*}{$\begin{array}{l}\text { Years enrolled } \\
\text { in education }\end{array}$} &, 16 & 198 & 37.4 & 62 & 36.5 \\
\hline & 16 and above & 332 & 62.6 & 109 & 63.7 \\
\hline \multirow[t]{2}{*}{ Occupation } & Managers and professionals & 320 & 60.3 & 74 & 40.2 \\
\hline & $\begin{array}{l}\text { Non-managers and } \\
\text { non-professional }\end{array}$ & 211 & 39.7 & 11 & 59.8 \\
\hline
\end{tabular}

Note: Missing numbers from each category are not included in this table.

We therefore focused our attention on age, gender, level of education and occupation. Based on this caveat, we propose the following hypotheses.

H4a: When controlling for occupation, the managerial/professional respondents from both countries will manifest more cultural similarities and thus national cultural differences will diminish significantly across all dimensions.

H4b: When controlling for age, the younger respondents from both countries will manifest more cultural similarities and thus national cultural differences will diminish significantly across all dimensions.

H4c: When controlling for levels of education, the higher the level of education of the respondents from the two countries, the greater the cultural value overlap will be among the respondents of both the countries; the less educated the respondents are, the greater the chances of inter-country cultural differences are.

Earlier studies on gender suggest that traditions as well as the corporate world are responsible for shaping females' cultural value system (Ashwin 2000; Adler 2002; Woldu and Budhwar 2011). Hence, we believe that women, as a result of the environment they live in, will manifest certain specific cultural values that may differ from those of men (e.g. Caligiuri and Cascio 1998; Napier and Taylor 2002; Adler and Gunderson 2008). Recent studies by Woldu and Budhwar (2011) and Budhwar et al. (2008) reveal that female respondents from Central East European countries, the former Soviet satellite states and India compared to their male counterparts show more cultural variations among themselves. Woldu and Budhwar (2011) argue that females compared to their male counterparts demonstrate relatively weaker cultural homogeneity, and as a result, one finds more variations among females in most cultural dimensions than their male counterparts from the respective countries. Hence, on the basis of such studies, we propose two hypotheses with regard to the cultural values of females in both Poland and Turkey.

H5a: Female respondents from both Poland and Turkey will culturally differ from their respective male counterparts on all cultural dimensions.

Having suggested the above hypothesis for testing it is believed that although females in most countries have historically passed through such a condition, it will be logical to assume that the social mobility and economic empowerment could differ from country to country. For example, Ashwin (2000) states that the former Soviet Union and the former 
Central and East European countries had attempted to neutralize the pre-existing historical gender-based socioeconomic differences. However, a close observation on many of these countries during the era of postindustrialization and post-communism clearly demonstrates that the so-called 'gender equality and social justice' has been only in decree or too slow to bring any significant change that could improve the social and economic condition of women (also see Woldu and Budhwar 2011). Nevertheless, the socio-economic transformation that has been taking place in most emerging nations such as Poland coupled with the ongoing democratization of societies is believed to incrementally increase the mobility of women.

On the contrary, in traditional societies, especially in Muslim societies such as Turkey, women are more likely to have the burden of raising families and might be more confined to their homes. Thus, Turkish women, more than their male counterparts, will experience social pressure and will be expected to carry the burden of taking care of the young and the old, whereas Turkish males are expected and encouraged to move farther from their birthplace areas and thus they have a higher chance of leaving their homes and migrating to many previously unknown local and international destinations. Though this scenario is also practiced in most of the former Central East European countries (Issopowa 2000; Kiblitskaya 2000), including Poland (Woldu and Budhwar 2011), Polish females are expected to be relatively more mobile than their Turkish counterparts. Based on this assumption, it can be stated that the Turkish females may demonstrate fewer traits of interactions with their female counterparts from other countries. These conditions suggest that Turkish women compared to Polish women might show stronger differences in values than their men counterparts. Hence, the following hypothesis is proposed.

H5b: Turkish male respondents will show more cultural similarities with Polish male respondents than would Turkish female with their respective Polish female counterparts.

As the result of the limited mobility of women compared to men and their less likely exposure to the corporate world, it is fair to assume that females will demonstrate cultural traits that are gender specific. Accordingly, the Turkish female respondents compared to their Polish counterparts will manifest cultural traits that may clash with the capitalist value system. Hence, it is hypothesized that:

H5c: Turkish females compared to their Polish counterpart will demonstrate significantly stronger traits in AT, RNS and $\mathrm{HNG}$, and weaker traits in RI, RH and RNH.

\section{Research method}

Using the snowballing technique (i.e. contacts of contacts) in a number of universities and businesses, a total of 744 questionnaire surveys were collected from a diverse cross-section (based on age, gender, educational backgrounds, occupation and levels of work experience) of employees from Poland and Turkey. Table 2 provides descriptive statistics for the sample populations. All surveys were collected between 2004 and 2008. The data organization is dichotomist in nature. The dichotomist data system (see Table 2) is constructed to measure the assumptions underlined in the proposed hypotheses for this study.

The data included in the study were collected mainly from major and medium-sized cities in both countries. In the case of Turkey, the data were obtained from Istanbul (55\%) and Izmir (45\%), and in case of Poland mainly from Poznan (45\%), Warsaw, Leszno and 
Konin (a total of 55\%). Two higher educational institutions from Istanbul and Izmir coordinated the survey for Turkey, while the help of Poznan University of Economics in Poland administrated the Polish survey. The questionnaire was originally prepared in English, it was then translated into Polish and Turkish, and a carefully back-translation procedure was followed to avoid translation errors.

Research instrument

To assess the cultural values of the respondents, we employed the CPQ (Kluckholn and Strodtbeck 1961; Maznevski et al. 1995). The CPQ uses 79 items to measure 11 dimensions of culture on a scale of 1 (strongly disagree) to 7 (strongly agree). These 11 cultural dimensions are described in Table 1, along with an example from each dimension scale. For reasons provided above, our analysis focused on only six of these dimensions - AT, RH, RI, RNH, RNS and HNG.

\section{Controls}

In order to explore differences in value orientations between different demographic groups in our samples, we collected a range of demographic data, reflecting diversity in age, gender, educational level and occupations.

The descriptive and independent samples t-tests were used to analyze the data along with Levens's test for equality of variances. If assumption of homogeneity of variance was violated, a t-statistic for not equal variances was reported. The research question is restated in the null hypothesis formed followed by the statistical analysis. The null hypothesis dealt with six levels of independent variables and nine dependent variables for each country. The six levels of the independent variables were RI, RNS, HNG, RH, RNH and AT. The independent variables were countries, females, males, educated (.16 years), less educated (\# 16 years), younger (\# 35 years), older (.35 years), professional and managers, non-professional and managers. The null hypothesis is presented in nine groups that will correspond with the groups in which the data were analyzed.

In the case of the education variable, those achieving postgraduate education and above were coded as 1 and all others coded 0 . Age was coded 1 for those under 35 (young) and 0 for those who were 35 and over (old). In the case of gender, female $(\mathrm{F})$ variable was coded 1 , while male $(\mathrm{M})$ was coded as 0 , and finally occupation was coded 1 for managers/professionals and 0 for non-managers/professionals. We also included dummy variables for countries. Means, standard deviations, t-statistic and p-values are presented in Tables $3-15$.

Findings and discussion

Inter-country differences on six cultural dimensions

In order to have an overview of the cultural orientation scores of the two countries, independent sample t-tests were implied on the six cultural dimensions. Based on the outcome of the analysis (see Table 3), the following observations are worth reporting. Both Poland and Turkey scored the highest on harmonious relations to nature (RNH, 5.51 and 5.30), activities of thinking (AT, 5.39 and 5.45), and human relations (RI, 4.84 and 4.56). However, the results indicate that both countries demonstrate modest mean scores on human relations (RH, 4.49 and 4.28) but lowest on human relations to nature good/evil (HNG, 4.03 and 3.85) and relations to nature-subjugative (RNS, 3.27 and 3.53). 
Table 3. Independent sample t-tests on cultural dimensions for all samples.

\begin{tabular}{lccrl}
\hline Cultural dimension & $\begin{array}{c}\text { Poland (n 1/4 548) } \\
\text { M (SD) }\end{array}$ & $\begin{array}{c}\text { Turkey (n 1/4 196) } \\
\text { M (SD) }\end{array}$ & t-Statistic & p-Value \\
\hline RI & $4.84(0.77)$ & $4.56(0.80)$ & 4.304 & $0.000^{* *}$ \\
RNS & $3.27(0.98)$ & $3.53(0.96)$ & 23.192 & $0.001^{* *}$ \\
HNG & $4.03(0.89)$ & $3.85(1.06)$ & 2.137 & $0.033^{*}$ \\
RH & $4.49(0.77)$ & $4.28(0.86)$ & 3.058 & $0.002^{* *}$ \\
RNH & $5.51(0.69)$ & $5.30(0.76)$ & 3.393 & $0.001^{* *}$ \\
AT & $5.39(0.71)$ & $5.45(0.77)$ & 21.073 & 0.284 \\
\hline
\end{tabular}

Note: Levene's statistics showed that variances were equal for all dimensions. *p , 0.05; **p, 0.01 .

Based on the above results, it can be seen that Turks and Poles differ significantly from each other on all dimensions except on AT. This outcome provides strong support for H1. Furthermore, Turkey's manifested lower cultural traits in HNG compared to Poland's may suggest that its national culture can develop a greater warmth and tolerance to fellow individuals. This trait is a positive attribute to European integration. As more advanced nations have the tendency of scoring lower scores on such dimension (Woldu and Guo 1999; Budhwar et al. 2008), Turkey may be expected to be more adaptable to the principles of free market cultural value systems. Likewise, nations with lower traits in hierarchical behavior prefer flatter organizational structures and friendly business environment (e.g. Gupta and Hanges 2004; House et al. 2004; Woldu et al. 2006; Adler and Gunderson 2008). Indeed, this also means that Turkey by scoring lower mean on RH may appear to be culturally more fitting with advanced nations such as the EU members, more receptive to entrepreneurial and pluralist ideas, and more likely to foster a more participatory management style compared to Poland. However, in the case of activities of thinking (AT), the study was not able to find any significant cultural difference between the two countries. Turkey's significantly lower mean scores than Poland on RNH ( $1 / 43.39 * *)$ and $\mathrm{RI}\left(\mathrm{t} 1 / 44.30^{* *}\right)$ also imply that Turkey might be more culturally compatible with western countries than Poland on these three dimensions.

Table 4. Intra-country cultural value differences based on gender.

\begin{tabular}{llcrrl}
\hline \multirow{2}{*}{ Dimensions } & Country & $\begin{array}{c}\text { Females } \\
\text { M (SD) }\end{array}$ & $\begin{array}{c}\text { Males } \\
\text { M (SD) }\end{array}$ & t-Value & p-Value \\
\hline RI & Poland & $4.90(0.76)$ & $4.76(0.78)$ & 1.988 & $0.047^{*}$ \\
& Turkey & $4.60(0.76)$ & $4.61(0.78)$ & 20.113 & 0.910 \\
RNS & Poland & $3.40(0.96)$ & $3.11(0.99)$ & 3.399 & $0.001^{* *}$ \\
& Turkey & $3.37(0.90)$ & $3.57(0.98)$ & 21.349 & 0.179 \\
HNG & Poland & $4.07(0.88)$ & $3.98(0.89)$ & 1.196 & 0.232 \\
& Turkey & $3.46(0.91)$ & $3.99(1.10)$ & 23.457 & $0.001^{* *}$ \\
RH & Poland & $4.48(0.78)$ & $4.48(0.76)$ & 20.001 & 0.999 \\
& Turkey & $4.10(0.81)$ & $4.36(0.88)$ & 22.005 & $0.046^{*}$ \\
RNH & Poland & $5.51(0.70)$ & $5.51(0.63)$ & 20.007 & 0.994 \\
& Turkey & $5.43(0.88)$ & $5.26(0.69)$ & 1.434 & 0.153 \\
AT & Poland & $5.42(0.68)$ & $5.33(0.75)$ & 1.494 & 0.136 \\
& Turkey & $5.63(0.68)$ & $5.39(0.83)$ & 2.116 & $0.036^{*}$ \\
\hline
\end{tabular}


Note: Levene's statistics showed that variances were equal for all dimensions except for HNG in the case of Turkey. *p, $0.05 ; * * p, 0.01$. 
Table 5. Intra-cultural value differences based on two levels of education.

\begin{tabular}{llccrl}
\hline \multirow{2}{*}{ Dimensions } & Country & $\begin{array}{c}\text { Educated (. 16 yrs) } \\
\text { M (SD) }\end{array}$ & $\begin{array}{c}\text { Less educated (\# 16 yrs) } \\
\text { M (SD) }\end{array}$ & t-Value & p-Value \\
\hline \multirow{2}{*}{ RI } & Poland & $4.77(0.78)$ & $4.94(0.73)$ & 22.533 & $0.012^{*}$ \\
& Turkey & $4.77(0.75)$ & $4.48(0.78)$ & 2.380 & $0.018^{*}$ \\
\multirow{2}{*}{ RNS } & Poland & $3.18(0.94)$ & $3.43(1.03)$ & 22.944 & $0.003^{* *}$ \\
& Turkey & $3.34(0.92)$ & $3.72(0.95)$ & 22.535 & $0.012^{*}$ \\
\multirow{2}{*}{ HNG } & Poland & $3.99(0.90)$ & $4.11(0.83)$ & 21.531 & 0.126 \\
\multirow{2}{*}{ RH } & Turkey & $3.60(1.11)$ & $4.12(0.94)$ & 23.051 & $0.003^{* *}$ \\
& Poland & $4.46(0.78)$ & $4.54(0.74)$ & 21.176 & 0.240 \\
RNH & Turkey & $4.01(0.91)$ & $4.58(0.63)$ & 24.888 & $0.000^{* *}$ \\
& Poland & $5.47(0.67)$ & $5.57(0.66)$ & 21.595 & 0.111 \\
AT & Turkey & $5.44(0.72)$ & $5.21(0.81)$ & 1.960 & 0.052 \\
& Poland & $5.32(0.74)$ & $5.46(0.64)$ & 22.379 & $0.018^{*}$ \\
& Turkey & $5.50(0.80)$ & $5.48(0.74)$ & 0.176 & 0.861 \\
\hline
\end{tabular}

Note: Levene's statistics showed that variances were equal for all dimensions except for HNG in the case of Turkey. *p , 0.05 ; **p , 0.01 .

However, our findings also show that Turkey scores a significantly higher mean score than Poland on subjugative relations to nature in RNS ( $\left.11 / 423.19^{* *}\right)$. This may signify that Turkey compared to Poland may not be completely compatible with EU's value system, at least with regard to this cultural dimension. In conclusion, our findings may suggest that Turkey demonstrates higher traits of cultural values on most of the criteria, which implies a more ready acceptance of free market philosophy, compared to the cultural traits manifested by Poland.

Intra-country cultural dynamics among demographic groups

Gender-based differences

When controlling for gender, females in Poland differed from their male counterparts only on RI and RNS, indicating that they scored significantly higher on both cultural

Table 6. Intra-country cultural value differences based two categories of occupation.

\begin{tabular}{llccrl}
\hline Dimensions & Country & $\begin{array}{c}\text { Professional } \\
\text { and managers } \\
\text { M (SD) }\end{array}$ & $\begin{array}{c}\text { Non-professional } \\
\text { and non-managers } \\
\text { M (SD) }\end{array}$ & t-Value & p-Value \\
\hline RI & Poland & $4.76(0.80)$ & $4.95(0.71)$ & 22.752 & $0.006^{* *}$ \\
& Turkey & $4.97(0.78)$ & $4.38(0.67)$ & 5.393 & $0.000^{* *}$ \\
RNS & Poland & $3.17(0.96)$ & $3.42(1.00)$ & 22.895 & $0.004 * *$ \\
& Turkey & $2.98(0.79)$ & $3.85(0.88)$ & 26.828 & $0.000^{* *}$ \\
HNG & Poland & $3.98(0.93)$ & $4.11(0.80)$ & 21.706 & 0.089 \\
& Turkey & $3.36(1.05)$ & $4.13(0.97)$ & 25.139 & $0.000^{* *}$ \\
RH & Poland & $4.56(0.79)$ & $4.37(0.73)$ & 2.915 & $0.004 * *$ \\
& Turkey & $3.84(0.88)$ & $4.53(0.72)$ & 25.627 & $0.000^{* *}$ \\
RNH & Poland & $5.57(0.64)$ & $5.42(0.70)$ & 2.510 & $0.012^{*}$ \\
\multirow{2}{*}{ AT } & Turkey & $5.64(0.67)$ & $5.08(0.73)$ & 5.168 & $0.000^{* *}$ \\
& Poland & $5.42(0.70)$ & $5.31(0.71)$ & 1.759 & 0.079 \\
& Turkey & $5.81(0.70)$ & $5.24(0.76)$ & 5.116 & $0.000^{* *}$ \\
\hline
\end{tabular}


Note: Levene's statistics showed that variances were equal for all dimensions except for HNG in the case of Turkey. *p, $0.05 ; * * p, 0.01$. 
Table 7. Intra-country cultural differences based on level of age categories.

\begin{tabular}{|c|c|c|c|c|c|}
\hline Dimensions & Country & $\begin{array}{c}\text { Younger (,35 yrs) } \\
\text { M (SD) }\end{array}$ & $\begin{array}{l}\text { Older (\$35 yrs) } \\
\text { M (SD) }\end{array}$ & t-Value & p-Value \\
\hline RI & Poland & $4.84(0.75)$ & $4.83(0.77)$ & 0.048 & 0.961 \\
\hline RNS & $\begin{array}{l}\text { Turkey } \\
\text { Poland }\end{array}$ & $\begin{array}{l}4.46(0.71) \\
3.19(0.96)\end{array}$ & $\begin{array}{l}5.00(0.83) \\
3.34(0.99)\end{array}$ & $\begin{array}{l}24.328 \\
21.711\end{array}$ & $\begin{array}{l}0.000 * * \\
0.088\end{array}$ \\
\hline HNG & Turkey & $3.68(0.95)$ & $3.05(0.83)$ & $\begin{array}{r}4.327 \\
502\end{array}$ & $0.000 * *$ \\
\hline & Turkey & $3.94(1.02)$ & $3.48(0.94)$ & 2.599 & $0.010 * *$ \\
\hline $\mathrm{RH}$ & $\begin{array}{l}\text { Poland } \\
\text { Turkey }\end{array}$ & $\begin{array}{l}4.33(0.76) \\
4.40(0.82)\end{array}$ & $\begin{array}{l}4.65(0.74) \\
3.88(0.86)\end{array}$ & $\begin{array}{r}24.934 \\
3.685\end{array}$ & $\begin{array}{l}0.000 * * \\
0.000 * *\end{array}$ \\
\hline RNH & $\begin{array}{l}\text { Poland } \\
\text { Turkey }\end{array}$ & $\begin{array}{l}5.37(0.66) \\
5.20(0.77)\end{array}$ & $\begin{array}{l}5.66(0.65) \\
5.59(0.70)\end{array}$ & $\begin{array}{l}25.107 \\
23.084\end{array}$ & $\begin{array}{l}0.000 * * \\
0.002 * *\end{array}$ \\
\hline AT & $\begin{array}{l}\text { Poland } \\
\text { Turkey }\end{array}$ & $\begin{array}{l}5.32(0.72) \\
5.36(0.75)\end{array}$ & $\begin{array}{l}5.45(0.69) \\
5.78(0.80)\end{array}$ & $\begin{array}{l}22.153 \\
23.260\end{array}$ & $\begin{array}{l}0.032 * \\
0.001 * *\end{array}$ \\
\hline
\end{tabular}

Note: Levene's statistics showed that variances were equal for all dimensions except for HNG in the case of Turkey. *p, $0.05 ; * * \mathrm{p}, 0.01$.

dimensions. However, the output in Table 4 suggests that Turkish females compared to their male counterparts scored significantly lower on cultural traits of HNG and RH but higher on AT. This would mean that the Polish females compared to their male counterparts would manifest significantly higher traits of individualism, but also tend to accept more unequal distribution of power. Meanwhile, the Turkish females demonstrate more culturally fitness with the cultural expectations of most economically and socially developed countries, including the EU members (e.g. Hofstede 1983; Woldu et al. 2006; Adler and Gunderson 2008). Agreeably, in most advanced countries, where economic development and social equity go hand in hand, one expects citizens of such nations to be less bias toward fellow human beings, i.e. low HNG (Adler and Gunderson 2008; Budhwar et al. 2008) and tend to be associated with less hierarchical human relations, i.e. low RH (Laurent 1983; Woldu et al. 2006). Hence, based on the analysis of the outcome presented in Table 4, we can conclude that H5a is partially supported. Furthermore, with regard to our investigation whether Turkish female due to the doctrine of Islam and the non-western cultural influence would manifest values that could clash with the ideas of free market economy, the study found that such assumption is not supported by the findings. In fact, the Turkish females compared to their male counterparts manifest more individualism, less bias toward fellow human beings and are less hierarchical. As a result, H5c is rejected (compare the findings of Table 3 with Tables 8 and 9).

Table 8. Independent sample t-tests on cultural dimensions for females.

\begin{tabular}{lcccc}
\hline Cultural dimension & $\begin{array}{c}\text { Poland (n 1/4 167) } \\
\text { M (SD) }\end{array}$ & $\begin{array}{c}\text { Turkey (n 1/4 42) } \\
\text { M (SD) }\end{array}$ & t-Statistic & p-Value \\
\hline RI & $4.83(0.77)$ & $4.61(0.70)$ & 1.701 & 0.091 \\
RNS & $3.36(0.92)$ & $3.32(0.80)$ & 0.236 & 0.814 \\
HNG & $4.05(0.91)$ & $3.39(0.98)$ & 4.131 & $0.000^{* *}$ \\
RH & $4.46(0.76)$ & $3.92(0.85)$ & 3.974 & $0.000^{* *}$ \\
RNH & $5.47(0.74)$ & $5.50(0.81)$ & 20.224 & 0.823 \\
AT & $5.38(0.69)$ & $5.57(0.68)$ & 21.577 & 0.116 \\
\hline
\end{tabular}


*p, $0.05 ; * * \mathrm{p}, 0.01$. 
Table 9. Independent sample t-tests on cultural dimensions for males.

\begin{tabular}{lccrl}
\hline Cultural dimension & $\begin{array}{c}\text { Poland (n 1/4 371) } \\
\text { M (SD) }\end{array}$ & $\begin{array}{c}\text { Turkey (n 1/4 144) } \\
\text { M (SD) }\end{array}$ & t-Statistic & p-Value \\
\hline RI & $4.84(0.77)$ & $4.59(0.80)$ & 3.264 & $0.001^{* *}$ \\
RNS & $3.23(1.01)$ & $3.56(0.97)$ & 23.433 & $0.001^{* *}$ \\
HNG & $4.02(0.88)$ & $3.96(1.06)$ & 0.575 & 0.566 \\
RH & $4.50(0.77)$ & $4.37(0.84)$ & 1.706 & 0.089 \\
RNH & $5.53(0.64)$ & $5.25(0.76)$ & 3.961 & $0.000^{* *}$ \\
AT & $5.38(0.72)$ & $5.43(0.81)$ & 20.666 & 0.506 \\
\hline
\end{tabular}

$* \mathrm{p}, 0.05 ; * * \mathrm{p}, 0.01$.

Table 10. Independent sample t-tests on cultural dimensions for educated (.16 years).

\begin{tabular}{lccrl}
\hline Cultural dimension & $\begin{array}{c}\text { Poland (n 1/4 332) } \\
\text { M (SD) }\end{array}$ & $\begin{array}{c}\text { Turkey (n 1/4 109) } \\
\text { M (SD) }\end{array}$ & t-Statistic & p-Value \\
\hline RI & $4.77(0.78)$ & $4.76(0.75)$ & 0.117 & 0.907 \\
RNS & $3.18(0.94)$ & $3.34(0.92)$ & 21.607 & 0.109 \\
HNG & $3.99(0.90)$ & $3.60(1.11)$ & 3.316 & $0.001^{* *}$ \\
RH & $4.46(0.78)$ & $4.01(0.91)$ & 5.046 & $0.000^{* *}$ \\
RNH & $5.47(0.67)$ & $5.44(0.72)$ & 0.397 & 0.691 \\
AT & $5.32(0.74)$ & $5.50(0.80)$ & 22.263 & $0.024^{*}$ \\
\hline
\end{tabular}

$* \mathrm{p}, 0.05 ; * * \mathrm{p}, 0.01$.

Education-based differences

When controlling for education, the outcomes of the study indicate that there are more cultural variations between the value systems of individuals with higher and lower years of education in both countries, but more variations between the two groups are more visible in the case of Turkey than Poland (see Table 5 for details). While examining the intra-country cultural dynamics for Poland, it is worth noting that respondents with 16 and more years of education compared to their less educated counterparts demonstrate significantly lower mean scores on RI, RNS and AT, while the Turkish groups demonstrated significantly lower means on RNS, HNG and RH, but higher scores on RI and RNH compared to their less educated counterparts. Hence, it can be stated that both countries share similar cultural values in subjugative relations to nature (RNS). However, it can be deduced from this analysis that Turkish respondents with relatively higher level of education will tend to manifest more cultural patterns that fit with those of most advanced

Table 11. Independent sample t-tests on cultural dimensions for less educated (\#16 years).

\begin{tabular}{lccrl}
\hline Cultural dimension & $\begin{array}{c}\text { Poland (n 1/4 198) } \\
\text { M (SD) }\end{array}$ & $\begin{array}{c}\text { Turkey (n 1/4 62) } \\
\text { M (SD) }\end{array}$ & t-Statistic & p-Value \\
\hline RI & $4.95(0.73)$ & $4.48(0.78)$ & 4.369 & $0.000^{* *}$ \\
RNS & $3.43(1.03)$ & $3.72(0.95)$ & 21.941 & 0.053 \\
HNG & $4.11(0.83)$ & $4.12(0.95)$ & 20.016 & 0.988 \\
RH & $4.54(0.74)$ & $4.58(0.63)$ & 20.418 & 0.676 \\
RNH & $5.57(0.66)$ & $5.21(0.81)$ & 3.188 & $0.002^{* *}$ \\
AT & $5.46(0.64)$ & $5.48(0.74)$ & 20.219 & 0.827 \\
\hline
\end{tabular}


*p, $0.05 ; * * \mathrm{p}, 0.01$. 
Table 12. Independent sample t-tests on cultural dimensions for professional and managers.

\begin{tabular}{lccrl}
\hline Cultural dimension & $\begin{array}{c}\text { Poland (n 1/4 320) } \\
\text { M (SD) }\end{array}$ & $\begin{array}{c}\text { Turkey (n 1/4 74) } \\
\text { M (SD) }\end{array}$ & t-Statistic & p-Value \\
\hline RI & $4.76(0.80)$ & $4.97(0.78)$ & 22.024 & $0.044^{*}$ \\
RNS & $3.17(0.96)$ & $2.98(0.79)$ & 1.755 & 0.082 \\
HNG & $3.98(0.93)$ & $3.36(1.05)$ & 5.040 & $0.000^{* *}$ \\
RH & $4.56(0.79)$ & $3.84(0.88)$ & 6.950 & $0.000^{* *}$ \\
RNH & $5.57(0.64)$ & $5.64(0.67)$ & 20.865 & 0.388 \\
AT & $5.42(0.70)$ & $5.81(0.70)$ & 24.296 & $0.000^{* *}$ \\
\hline
\end{tabular}

$* \mathrm{p}, 0.05 ; * \mathrm{p}, 0.01$.

Table 13. Independent sample t-tests on cultural dimensions for non-professional and non-managers.

\begin{tabular}{lccrl}
\hline Cultural dimension & $\begin{array}{c}\text { Poland (n 1/4 211) } \\
\text { M (SD) }\end{array}$ & $\begin{array}{c}\text { Turkey (n 1/4 110) } \\
\text { M (SD) }\end{array}$ & t-Statistic & p-Value \\
\hline RI & $4.95(0.71)$ & $4.37(0.66)$ & 7.045 & $0.000^{* *}$ \\
RNS & $3.42(1.00)$ & $3.85(0.88)$ & 23.943 & $0.000^{* *}$ \\
HNG & $4.12(0.80)$ & $4.13(97)$ & 20.179 & 0.858 \\
RH & $4.37(0.73)$ & $4.53(0.72)$ & 21.957 & 0.051 \\
RNH & $5.42(0.70)$ & $5.09(0.73)$ & 3.942 & $0.000^{* *}$ \\
AT & $5.31(0.71)$ & $5.24(0.76)$ & 0.797 & 0.426 \\
\hline
\end{tabular}

$* \mathrm{p}, 0.05 ; * \mathrm{p}, 0.01$.

western countries than do the Polish educated respondents. Earlier studies show that more educated and professional individuals from western countries tend to show lower cultural traits of RI (Woldu et al. 2006), RNS (Budhwar et al. 2008), HNG and RH (Woldu and Guo 1999). However, when intra-country cultural differences are analyzed, H4c is supported only partially (compare Table 5 with Tables 10 and 11).

\section{Occupation-based differences}

With regard to the variable of occupation intra-country value, differences are prevalent on all cultural dimensions for Turkey and most for Poland (not AT and HNG although these may be deemed marginally significant). Results in Table 6 show that the Polish professional and manager respondents scored significantly lower on RI and RNS, but higher on RH and RNH compared to the non-professional and non-manager respondents

Table 14. Independent sample t-tests on cultural dimensions for 35 years or younger.

\begin{tabular}{lccrl}
\hline Cultural dimension & $\begin{array}{c}\text { Poland (n 1/4 274) } \\
\text { M (SD) }\end{array}$ & $\begin{array}{c}\text { Turkey (n 1/4 140) } \\
\text { M (SD) }\end{array}$ & t-Statistic & p-Value \\
\hline RI & $4.84(0.75)$ & $4.46(0.71)$ & 4.870 & $0.000^{* *}$ \\
RNS & $3.20(0.98)$ & $3.68(0.95)$ & 24.838 & $0.000^{* *}$ \\
HNG & $4.01(0.87)$ & $3.94(1.02)$ & 0.658 & 0.511 \\
RH & $4.33(0.76)$ & $4.40(0.82)$ & 20.879 & 0.380 \\
RNH & $5.37(0.66)$ & $5.20(0.77)$ & 2.180 & $0.030^{*}$ \\
AT & $5.32(0.72)$ & $5.36(0.75)$ & 20.547 & 0.585 \\
\hline
\end{tabular}


*p, $0.05 ; * * \mathrm{p}, 0.01$. 
Table 15. Independent sample t-tests on cultural dimensions for above 35 years.

\begin{tabular}{lccrl}
\hline Cultural dimension & $\begin{array}{c}\text { Poland (n 1/4 261) } \\
\text { M (SD) }\end{array}$ & $\begin{array}{c}\text { Turkey (n 1/4 47) } \\
\text { M (SD) }\end{array}$ & t-Statistic & p-Value \\
\hline RI & $4.83(0.79)$ & $5.00(0.83)$ & 21.352 & 0.177 \\
RNS & $3.34(0.99)$ & $3.05(0.83)$ & 1.890 & 0.060 \\
HNG & $4.05(0.91)$ & $3.48(1.13)$ & 3.233 & $0.002^{* *}$ \\
RH & $4.65(0.74)$ & $3.88(0.86)$ & 6.349 & $0.000^{* *}$ \\
RNH & $5.66(0.65)$ & $5.59(0.68)$ & 0.637 & 0.524 \\
AT & $5.45(0.69)$ & $5.78(0.80)$ & 22.938 & $0.004^{* *}$ \\
\hline
\end{tabular}

$* \mathrm{p}, 0.05 ; *$ p, 0.01 .

from their country. In the case of Turkey, professional and manager respondents scored significantly lower on RNS, HNG, RH, but higher on RI, RNH and AT compared to their non-professional and non-manager counterparts.

However, in the case of Poland, the outcome of the study overall resembles to that of Turkey, which indicates that Polish professional and manager group scored significantly higher score on RH than the non-professional and manager group from its country (see Table 6). This also suggests that the outcomes in the case of Poland and Turkey will fit with those western cultural values in all cultural dimensions, except for RI and RH for Poland. In the case of $\mathrm{RI}$, the outcome is not contradictory to the observation of most emerging economy countries as reflected in the studies of Woldu and colleagues (see Woldu and Gou 1999; Budhwar et al. 2008; Woldu and Budhwar 2011). However, a significantly lower RH score by Turkish professional and manager group than their Polish counterparts means that Turkish professional and manager group will fit better with the western culture that is known for the preference of flatter organizational behavior and democratic participatory management style (Laurent 1983; Adler and Gunderson 2008). However, with the exception of the case of RH and RI, it can be concluded that the professional and managerial population from both countries will have more compatible value system with the advanced EU countries, than their respective non-professional and non-managerial citizens. Hence, H4a is supported.

\section{Age-based differences}

Results in Table 7 show that there are more intra-country cultural variations in the case of Turkey than Poland such that younger Turkish respondents compared to their older counterparts demonstrate significantly lower scores on RI, RNH and AT, but higher scores on RNS, HNG and RH. On the contrary, younger Polish respondents demonstrate significantly lower scores on RH, RNH and AT as compared to the older respondents. Such results indicate that there is more generational cultural gap in Turkey than in Poland. Second, looking at the directions of the values the Turkish young respondents' cultural values, they appear to go in the opposite direction of cultural expectation in the West, while the Polish young respondent value system fits better with the values reflected in most advanced economies as indicated in previous studies (see Hofstede 1983; Woldu et al. 2006; Budhwar et al. 2008; Adler and Gunderson 2008).

Inter-country cultural dynamics

The objective of the inter-country analysis in Phase 3, unlike the inter-country analysis discussed in Phase 1 and displayed in Table 3, is to integrate the objectives outlined in 
Phases 1 and 2. Hence, the analysis, which is derived from the outputs displayed in Tables $8-15$, responds to two important issues that are the main themes of the paper.

(a) Whether the cross-country cultural differences observed in Phase 1 gets narrower or wider.

(b) Whether there is an overlap of values among certain demographic groups of the two countries.

Gender-based dynamics

The gender-based cultural differences between Poland and Turkey demonstrates the following observations. Independent sample t-test between female respondents from both countries show that the Polish female respondents compared to their Turkish counterparts scored significantly higher means on HNG $\left(\mathrm{t} 1 / 44.13^{* *}\right)$ and $\mathrm{RH}(\mathrm{t} 1 \mathrm{1} / 4.97 * *)$ (see Table 8). From the finding, we can deduce two important observations. First, the finding with regard to the two dimensions, as presented in Table 8 supplements the output displayed in Table 3. Second, on both dimensions, the Turkish females compared to their Polish counterparts appear to fit better with the cultural expectations of most advanced and western countries. Earlier, studies indicate that western societies compared to less developed countries tend to emphasize on both HNG and RH (see Woldu et al. 2006; Adler and Gunderson 2008). Independent sample ttest between the male respondents from both the countries shows that Polish males compared to their Turkish counterparts scored significantly higher on RI ( $\left.\mathrm{t}^{1 / 4} 3.26^{* *}\right)$ and $\mathrm{RNH}\left(\mathrm{t} 1 / 43.96^{* *}\right)$, and lower on RNS ( $\left.\mathrm{t}^{1 / 4} 23.43^{* *}\right)$. This also indicates that the Polish male compared to their female counterparts demonstrate rather more pro-western cultural traits than Turkish males.

The analysis presented in Tables 8 and 9 suggests that the inter-country cultural value differences that have been displayed earlier in Table 3 should be attributed to the female value differences, which are spelled out in Table 8 in the cases of RH and HNG, while the inter-country differences in RI, RNS and RNH can be attributed to the male value differences between the two countries as observed in Table 9. However, the study was not able to find intercultural differences for males on RI, HNG, RNH and RI, and for females on RNS and RNH. Hence, H5a is partially supported.

\section{Education-based dynamics}

When controlling for education, the analysis found that the Polish respondents with 16 and more years of education scored significantly higher on HNG (t 1/4 3.32**) and RH (t 1/4 5.05**) but lower on AT (t 1/4 22.26*) than their Turkish counterparts (see Table 10). However, when the analysis focuses on respondents with less than 16 years of education, the results show that Polish respondents compared to their Turkish counterparts scored significantly higher on RI ( 1 1 $1 / 4.37 * *)$ and $\mathrm{RNH}\left(\mathrm{t} 1 / 43.19^{* *}\right)$ (see Table 11$)$.

Based on the findings in Tables 10 and 11, it can be concluded that the Polish respondents with higher years of education demonstrate higher level of bias toward fellow human beings (HNG) and favor more hierarchical human relations $(\mathrm{RH})$. On the other hand, they tend to pay less attention to issues that might require thinking before taking any action (AT), compared to the Turkish groups.

This outcome has also been observed in earlier research, which compared Polish employees with others (see Siemienska 1994; Woldu et al. 2006). This also means that highly educated Poles compared to their Turkish counterparts might need more training on 
cultural sensitivity when working with other colleagues from other countries. Likewise, the highly educated Polish individuals compared to their Turkish counterparts seem to be fond of maintaining structured hierarchy in social relationship and organizations; hence, the former, more than the latter, may need to be flexible when conducting businesses operations and negotiations with northern European countries.

Contribution scholars such as Adler and Gunderson (2008) and Laurent (1983) indicate that advance European nations, especially the Scandinavian countries, tend to be more comfortable with less organizational structure and more personal autonomy in their day-to-day life. However, the fact that Polish educated group showing significantly low on AT than their Turkish counterparts would mean that they are quick in taking an action. This attitude for this category of groups makes Poland more compatible with the European culture. The results in Tables 10 and 11 suggest that the Turkish elite compared to their Polish counterpart, might not have difficulties in fitting with the Western European cultural expectations, whereas the less educated Turkish group compared to their Polish counterpart will need more training and adjustments. These findings therefore indicate that H5a is partially supported.

\section{Occupation-based dynamics}

First of all, the output with regard to the variable professional and managers of the two countries clearly indicates that the Turkish respondents compared to their Polish counterparts demonstrated significantly higher values on RI ( $\mathrm{t}$ $1 / 422.02 *$ ) and AT (t $\left.1 / 424.30^{* *}\right)$, but significantly lower scores on HNG (t $\left.1 / 45.04 * *\right)$ and RH (t 1/4 6.95**). Interestingly, the outcome with regard to the professional and managers' groups shows that the Turkish respondents compared to the Polish demonstrate significantly the tendency to move closer to the values that are reflected by the value systems of most mature western countries. As one can see, the divergence of Turkish professional and managerial respondent vis-a -vis that of Poland on RI, HNG, RH and AT is significantly visible (please compare Tables 3 and 14). Hence, H4a is rejected.

In case of the non-professional and non-managerial respondents, the Poles scored significantly lower means than their Turkish counterparts on RNS ( $\left.\mathrm{t}^{1 / 4} 23.94 * *\right)$, but higher on RI ( $\left.\mathrm{t}^{1 / 4} 7.05^{* *}\right)$ and $\mathrm{RNH}\left(\mathrm{t}^{1 / 4}\right.$ 3.94**). In conclusion, when the focus of our analysis is solely on professional and managerial respondents, unlike the case of inter-country output (differences displayed in Table 3), the outcome for the latter is significantly higher than the former. Second, with regard to the dimension AT, unlike the outcome in Table 3, the output as displayed in Table 12 reveals the presence of significant difference between the two countries. The difference on AT can be attributed to the high mean scores by Turkish professional and managerial groups. Hence, it can be concluded that the Turkish professional and managers more than their Polish counterparts seemed to demonstrate higher entrepreneurial, egalitarian and harmonious cultural traits.

On the contrary, with regard to non-professional and non-managerial employees, the Polish respondents compared to their Turkish counterparts demonstrate higher entrepreneurialism, less tolerance to non-egalitarian values and lower preference for hierarchical human relations. In short, the outcomes from both categories provide a unique perspective for international human resource strategists. On one hand, the Turkish professional and managers and the Polish non-professional and non-managers manifest cultural values that are more compatible with that of advance western countries, whereas, on other hand, the Polish professional and managers and the Turkish nonprofessional and non-managers demonstrate traits that are contrary to the values that are expected in 
advance western countries. Hence, these two groups might need special attention should international human resource strategists seek to bring cohesive manpower management practices in any international business operation, which involves the two occupational categories involving both countries.

Age-based dynamics

As viewed and discussed earlier in Phase 2, age-related intra-country differences presented in Table 7 clearly show that there is strong evidence that supports the presence of significant value differences between respondents with age less than 35 and 35 and above. This observation calls for the investigation of age factor in inter-country differences that are presented in Tables 12 and 13. When comparing younger (,35 years) Turkish and Polish respondents, one can see that the Polish score significantly higher on RI ( $\left.1 / 44.87^{* *}\right)$ and $\mathrm{RNH}\left(\mathrm{t} 1 / 42.18^{*}\right)$, but significantly lower on RNS ( $\left.\mathrm{t} 1 / 424.84^{* *}\right)$ (see Table 14). Nevertheless, when a comparative analysis is employed on respondents above 35 years of age, the following observations emerge (see Table 15 for details). The Polish respondents compared to their Turkish counterparts scored significantly higher on HNG (t 1/4 3.23**) and RH ( $\left.\mathrm{t}^{1 / 4} 6.35^{* *}\right)$, but lower on AT (t $1 / 4$ $22.94 * *)$. Hence, such outcome confirms rejection of $\mathrm{H} 4 \mathrm{~b}$.

Thus, it can be derived that the Polish younger respondents, compared to their Turkish counterparts, demonstrate receptive cultural traits to free market system as high score on individualism contributes positively to entrepreneurships (high RI) and harmonious relations to nature (high RNH); the latter leads to collaborative relations at the workplace. Likewise, the low score on subjugative dimension discourages an uneven distribution of power in society; such outcome contributes to egalitarian and democratic participation of employees at the workplace (Budhwar et al. 2008). These findings mirror the finding of inter-country differences explored in Table 3 . However, when one focuses on the older respondents, the outcome unlike in the case of inter-country finds no significant differences between the respondents of the two countries on individualism, subjugative and harmonious relations to nature, but finds significant difference in values between the two groups in the attitude of thinking. This indicates that H4b is partially supported. However, it is worth noting that the Polish younger generation seems to better embrace western cultural values than its Turkish counterparts.

\section{Conclusion and implications}

The purpose of this paper has been to compare and contrast the cultural value orientations of employees in Poland and Turkey, and to further examine cultural variations within these countries arising from individual demographic differences. We have demonstrated that culture varies significantly across and within these countries, and also varies with demographic characteristics.

We believe our findings should be helpful for international managers, and have made suggestions for how international firms can improve their management practices through better cultural awareness. International business managers should recognize group and subculture variations within national cultures, and benefit from differentiating their strategies on this basis while operating in different cross-national and cross-cultural settings (Deichmann, Eshghi, Haughton, Sayek and Teebagy 2003; Sparrow et al. 2009). This implies that foreign businesses may wish to develop different or separate strategies in their dealings with nations that are culturally diverse to them. 
The outcome of the study should be interpreted cautiously due to few obvious limitations such as small sample size, single time data collection, lack of support to some hypotheses and the poor reliability scores on five dimensions of the CPQ. Further, the surveys were conducted in urban centers, and one might wonder whether the outcome of the study will be applicable to the rural populations and to what extent. Nevertheless, within these limitations of the research, we believe the analysis has some useful messages for both managers and researchers.

Cultural awareness is well established as a key contributor to international business problems. Firms involved in international business cannot expect to succeed by using a uniform approach to their business activities in other countries or interactions with foreign business representatives (also see Adler and Gunderson 2008; Woldu and Budhwar 2011). Effective management requires adapting to variations in the business environment, including variations in human culture. The strategies of MNCs in areas such as HRM, negotiation style, form of ownership, business operation management and control including joint ventures may not be effective unless they adapt to the cultural characteristics of the people with whom they are working and doing business.

This observation is very relevant and provides vital information for any organization planning to conduct business in the two research countries. Based on the outcome of the study, it is clear that employees in both Poland and Turkey have very different cultural traits. It is important to acknowledge these substantial differences and especially among their respective demographic groups. The study also suggests that while national cultural differences will continue to exist, many of the differences tend to diminish when one controls for gender, age, education and occupation.

Given the potentially homogenizing cultural effects of factors such as widespread travel, higher education and the electronic media, variations in culture may be even more pronounced across under-researched nations such as Poland and Turkey. Firms moving into such countries should recognize that there is extensive cultural variation across them (Woldu and Budhwar 2011). Since cultural values also tend to vary by region within a country, to be effective, firms need to learn about the specific cultural characteristics of each country and region with which they interact and adapt their management practices on a case-by-case basis.

From a training perspective, future programs can be developed to prepare managers along the dominant cultural values of a given nation for better adjustment. This can lead to the development of both cultural intelligence and cultural agility.

From a research perspective, the usage of CPQ has yielded mixed reactions. It reconfirms the shortcomings of western instruments to other settings. Nevertheless, the three-phase analysis has helped to glean out the intricate differences and similarities across the two national and different demographic-based groups.

\section{References}

Adler, N.J. (2002), 'Global Managers: No Longer Men Alone,' The International Journal of Human Resource Management, 13, $743-760$.

Adler, N.J., and Gunderson, A. (2008), International Dimensions of Organizational Behavior (5th ed.), Andover, MA: SouthWestern Cengage Learning.

Ashwin, S., (ed.) (2000), Gender, State and Society in Soviet and Post-Soviet Russia, London: Rutledge.

Ball, D., McCulloch, W., Fratz, P., Geringer, M., and Minor, M. (2008), International Business: The Challenge of Global Competition, Boston, MA: McGraw-Hill/Irwin.

Benhabib, S., and Isiksel, T. (2006), 'Ancient Battles, New Prejudices, and Future Perspective: Turkey and the EU,' Constellations, $13,218-233$. 
Brewster, C., Mayrhofer, W., and Morley, M. (eds.) (2000), New Challenges for Human Resource Management in Europe, London: Macmillan.

Budhwar, P. (2012, June), 'Management of Human Resources in Foreign Firms Operating in India: The Role of HR in CountrySpecific Headquarters,' The International Journal of Human Resource Management, 23, 12, 2514 - 2531.

Budhwar, P.S., Woldu, H., and Ogbonna, E. (2008), 'A Comparative Analysis of Cultural Value Orientation of Indians and Migrant Indians in the USA,' International Journal of Cross Cultural Management, 8, $79-105$.

Caligiuri, P., and Cascio, W. (1998), 'Can We Send Her There? Maximizing the Success of Western Women on Global Assignments,' Journal of World Business, 33, $394-416$.

Carbaugh, R. (2009), International Economics, Andover, MA: South-Western Cengage Learning. Deichmann, J.I., Eshghi, A., Haughton,

D.M., Sayek, S., and Teebagy, N.C. (2003), 'Foreign Direct Investment in the Eurasian Transition States,' Eastern European Economics, 41, 5 - 34. Emrich, C., Denmark, F., Hartog, D.

(2004), 'Cross-Cultural Differences in Gender Egalitarianism: Implications for Organizations, and Leaders,' in The GLOBE Study of 62 Societies, eds. House et al., Thousand Oaks, CA: Sage, pp. $343-394$.

Gupta, V., Hanges, P. (2004), 'Regional and Climate Clustering of Societal Cultures,' in The GLOBE Study of 62 Societies, eds. House et al., Thousand Oaks, CA: Sage, pp. $178-217$.

Hoecklin, L. (1995), Managing Cultural Differences: Strategies for Competitive Advantage, New York: Addison-Wesley.

Hofstede, G. (1983), 'National Cultures in Four Dimensions,' International Studies of Management and Organization, 13, 1 - 2, $46-74$.

Hofstede, G., and Bond, H.M. (1984), 'Hofstede's Cultural Dimensions,' Journal of Cross-Cultural Psychology, 15,417 - 433.

House, R.J., Hanges, P.J., Javindan, M., Dorfman, P.W., and Gupta, V. (2004), Culture, Leadership, and Organizations: The Globe Study of 62 Societies, Thousand Oaks, CA: Sage.

Issopowa, O. (2000), 'From Duty to Pleasure? Motherhood in Soviet and Post-Soviet Russia,' in Gender, State and Society in Soviet and Post-Soviet Russia, ed. S. Ashwin, London: Routledge, pp. 30 - 54.

Kiblitskaya, M. (2000), 'Russia's Female Breadwinners: The Exchange of Subjective Experience,' in Gender, State and Society in Soviet and Post-Soviet Russia, ed. S. Ashwin, London: Routledge, pp. 55 - 57.

Kluckholn, F., and Strodtbeck, F.L. (1961), Variations in Value Orientations, New York: Greenwood Press.

Kostera, M. (1995), 'Differing Managerial Responses to Change in Poland,' Organizations Studies, 16, 673 - 697.

Laurent, A. (1983), 'The Cultural Diversity of Western Conceptions of Management,' International Studies of Management and Organization, 13, 75 - 96 .

Maznevski, M.L., DiStephano, J.J., and Nason, S.W. (1995), Cultural Perspectives Questionnaire, London/Ontario/Charlottesville, VA: The University of Western Ontario/ the University of Virginia.

Muftuler-Bac, M. (2002), 'Turkey in the EU's Enlargement Process: Obstacles and Challenges,' Mediterranean Politics, 7, 79 - 95 (AN 10545284).

Napier, N.K., and Taylor, S. (2002), 'Experiences of Women Professionals Abroad: Comparisons Across Japan, China and Turkey,' The International Journal of Human Resource Management, 13, 837 - 851.

Nyambegera, S.M., Sparrow, P., and Daniels, K. (2000), 'The Impact of Cultural Value Orientations on Individual HRM Preferences in Developing Countries: Lessons From Kenyan organizations,' The International Journal of Human Resource Management, 11, 4, 639 - 663.

Ozbilgin, M.F., and Woodward, D. (2004), 'Belonging and Otherness: Sex Equality in Banking in Turkey and Britain,' Gender, Work and Organization, 11, $668-688$.

Rajkiewicz, A. (1998), 'Procesy Migracji Zarobkowej w Polsce,' Seczty Nowkowe, Wyzsza Szkola Zarzadzania I Bankowosci, $1,265,90-107$.

Ralston, D.A., Holt, D.H., Terpstra, R.H., and Kai-Cheng, Y. (1997), 'The Impact of National Culture and Economic Ideology on Managerial Work Values: A Study of the United States, Russia, Japan, and China,' Journal of International Business Studies, $28,1,177-207$.

Sachs, J. (1993), Poland's Jump Start to a Market Economy, Cambridge, MA: MIT Press. 
Schwartz, S.H. (1992), 'Universals in the Content and Structure of Values: Theoretical Advances and Empirical Tests in 20 Countries,' in Advances in Experimental Social Psychology, ed. M.P. Zanna, San Diego, CA: Academic Press, pp. 1 - 65.

Siemienska, R. (1994), 'Women Managers in Poland: In Transition from Communism to Democracy,' in Competitive Frontiers: Women Managers in a Global Economy, eds. N. Adler and D. Israeli, Cambridge, MA: Blackwell, pp. 160 - 174.

Sparrow, P., Schuler, R.S., and Budhwar, P. (2009), 'Editors' Introduction: Developments in Cross-Cultural HRM,' in Major Works in International Human Resource Management (Vol. 3), eds. P. Budhwar, R. Schuler and P. Sparrow, London: Sage, pp. vii - xviii.

Sparrow, P., and Wu, P.C. (1998), 'Does National Culture Really Matter? Predicting HRM Preferences of Taiwanese Employees,' Employee Relations, 20, 1, 26 - 56.

Trompenaars, F. (1994), Riding the Waves of Culture, London: Economist Books.

Tung, R.L. (2008), 'The Cross-Cultural Research Imperative: The Need to Balance Cross-National vis-a'vis International Diversity,' Journal of International Business Studies, 39, $41-46$.

Tung, R.L., and Verbeke, A. (2010), 'Beyond Hofstede and GLOBE: Improving the Quality of Cross-Cultural Research,' Journal of International Business Studies, 41, 1259 - 1274.

Walumbwa, F.O., and Lawler, J.J. (2003), 'Building Effective Organizations: Transformational Leadership, Collectivist Orientation, Work-Related Attitudes and Withdrawal Behaviours in Three Emerging Economies,' The International Journal of Human Resource Management, 14, 7, 1083 - 1101.

Weinstein, S., and Obloj, M. (2002), 'Strategic and Environmental Determinants of HRM Innovations in Post-Socialist Poland,' The International Journal of Human Resource Management, 13, 642 - 659.

Woldu, H., and Biederman, M. (1999), 'The Dynamics of Organizational Culture in the Private, Government, and SemiGovernment Companies in Poland,' Journal of East European Studies, 4, 306 - 321.

Woldu, H., and Budhwar, P. (2011), 'Cultural Value Orientations of the Former Communist Countries: A Gender Based Analysis,' The International Journal of Human Resource Management, 22, 1365 - 1386.

Woldu, H., Budhwar, P., and Parkes, C. (2006), 'A Cross-National Comparison of Value Orientation of Indians, Polish, Russian and American Employees,' The International Journal of Human Resource Management, 17, 1076 - 1094.

Woldu, H., and Guo, I. (1999), 'Understanding Cultural Differences Between Russia and North America,' in Management Education for Countries in Transition, eds. M. Frazer and M. Chatterji, London: Macmillan, pp. $31-45$. 